\title{
Use of recombinant human soluble thrombomodulin in patients with sepsis-induced disseminated intravascular coagulation after intestinal perforation
}

\author{
Takashi Tagami 1,2*, Hiroki Matsui ${ }^{2}$, Kiyohide Fushimi ${ }^{3}$ and Hideo Yasunaga ${ }^{2}$ \\ 1 Department of Emergency and Critical Care Medicine, Nippon Medical School, Tokyo, Japan \\ 2 Department of Clinical Epidemiology and Health Economics, School of Public Health, Graduate School of Medicine, The University of Tokyo, Tokyo, Japan \\ ${ }^{3}$ Department of Health Informatics and Policy, Graduate School of Medicine, Tokyo Medical and Dental University, Tokyo, Japan
}

\section{Edited by:}

Zsolt Molnár, University of Szeged, Hungary

\section{Reviewed by:}

Lars Jakob Bjertnaes, University of Tromsø, Norway

Vsevolod V. Kuzkov, Northern State

Medical University, Russia

*Correspondence:

Takashi Tagami, Department of

Emergency and Critical Care

Medicine, Nippon Medical School,

1-1-5 Sendagi, Bunkyo-ku, Tokyo

113-8603, Japan

e-mail: t-tagami@nms.ac.jp
Background: Anticoagulant therapy has been evaluated with respect to its potential usefulness in reducing the high mortality rates associated with severe sepsis, including sepsis-induced disseminated intravascular coagulation (DIC) after intestinal perforation. We examined the hypothesis that recombinant human soluble thrombomodulin (rhTM) is effective in the treatment of patients with septic shock with sepsis-induced DIC after laparotomy for intestinal perforation.

Methods:We performed propensity-score and instrumental variable analyses of the Japanese Diagnosis Procedure Combination in-patient database, a nationwide administrative database. The main outcome was 28-day in-hospital all-cause mortality.

Results: We categorized eligible patients $(n=2202)$ from 622 hospitals into the rhTM group ( $n=726)$ and control group $(n=1476)$. Propensity-score matching created 621 matched pairs of patients with and without rhTM. There was neither significant difference in 28-day mortality between the two groups in the unmatched analysis (rhTM vs. control, 25.3 vs. $23.4 \%$, respectively; difference, $1.9 \% ; 95 \% \mathrm{Cl},-1.9$ to 5.7$)$ nor in the propensity-scorematched analysis (rhTM vs. control, 26.1 vs. $24.8 \%$, respectively; difference, $1.3 \% ; 95 \%$ $\mathrm{Cl},-3.6$ to 6.1). The logistic analysis showed no significant association between the use of rhTM and the mortality in propensity-score-matched patients (OR, 1.1; $95 \% \mathrm{Cl}, 0.82-1.4)$. The instrumental variable analyses, using the hospital rhTM-prescribing proportion as the variable, found that receipt of rhTM was not associated with the reduction in the mortality (risk difference, $-6.7 \% ; 95 \% \mathrm{Cl},-16.4$ to 3.0 ).

Conclusion: We found no association between administration of rhTM and 28-day mortality in mechanically ventilated patients with septic shock and concurrent DIC after intestinal perforation.

Keywords: anticoagulants, disseminated intravascular coagulation, outcomes assessment, surgery, sepsis

\section{INTRODUCTION}

Severe sepsis is one of the most common causes of death in critically ill patients worldwide (1-4). Sepsis-induced disseminated intravascular coagulation (DIC) results in a poor outcome and is frequently observed among these patients $(2,5-7)$. Sepsis-induced DIC is a systemic process characterized by both thrombosis and hemorrhage (8-12). However, the treatment is generally limited to treatment of the underlying condition and administration of appropriate blood products $(9,11)$.

Recombinant human soluble thrombomodulin (rhTM; Asahi Kasei Pharma Co., Tokyo, Japan) is used clinically for DIC treatment in Japan $(13,14)$. Thrombomodulin is a thrombin receptor on the endothelial cell surface and plays a vital part in the regulation of DIC $(15,16)$. rhTM is composed of the active extracellular domain of thrombomodulin (13). Similar to membranebound thrombomodulin, rhTM binds to thrombin to inactivate coagulation, and the thrombin-rhTM complex activates protein $\mathrm{C}$ to produce activated protein C (APC). APC inactivates factors VIIIa and Va in the presence of protein $\mathrm{S}$, inhibiting further thrombin formation $(13,16)$. The clinical impact of rhTM on DIC were first examined in Japan as a phase- 3 trial showing that resolution of sepsis-induced DIC was better in patients treated with rhTM than in those treated with heparin (13). Although there was no significant difference in mortality between these two groups of patients $(13,17)$, the clinical use of rhTM was approved in Japan by the Japanese Ministry of Health, Labour and Welfare in 2008. Vincent et al. (18) recently reported the results of a multinational placebocontrolled trial (phase 2b). Although their study had inadequate power to detect statistical significance, the 28-day mortality rate in patients who received rhTM tended to be lower than that in patients who received standard care alone ( 17.8 vs. $21.6 \%$, respectively; one-sided $\log$-rank $p=0.17)(18)$. Based on these results, 
a multinational phase-3 trial of rhTM for sepsis-induced DIC (ClinicalTrials.gov Identifier: NCT01598831) is ongoing.

Previous interventional and epidemiological studies have suggested that the two major infection sites giving rise to sepsis are the lungs and abdomen (1-3). Although the causal pathogens, required interventions, recovery time course, severity of DIC, and mortality rates differ between the lungs and abdomen, infection at these two sites often results in sepsis-induced DIC $(1,6,19$, 20). Additionally, in a previous study of 6342 patients with severe pneumonia and sepsis-induced DIC, we found no significant association between the use of rhTM and the 28-day mortality rate (21). In contrast to our previous study on pneumonia (21), few studies have examined the association between rhTM use and mortality in patients with sepsis-induced DIC with a direct focus on abdominal sepsis and the use of a large sample.

The current study evaluated whether rhTM can reduce mortality in patients with sepsis-induced DIC after intestinal perforation confirmed by laparotomy.

\section{MATERIALS AND METHODS}

This study was approved by the institutional review board of The University of Tokyo, which waived the requirement for informed patient consent because of the anonymous nature of the data.

\section{DIC DIAGNOSIS AND rhTM USE IN JAPAN}

The Japanese Association for Acute Medicine (JAAM) guidelines were published in 2006 (7). These guidelines have prompted physicians to diagnose sepsis-induced DIC. The guidelines have been widely used in most of the recent reports from Japan $(8,12,22-24)$. The JAAM DIC scoring system includes the systemic inflammatory response syndrome score (score of 0 or 1), platelet count (score of 0,1 , or 3 ), fibrin/fibrinogen degradation product levels (score of 0 or 1 ), and prothrombin time ratio (score of 0,1 , or 3 ) (7, 25). DIC was diagnosed in patients with a total score of $\geq 4$ (7). The clinically approved dose of rhTM by the Japanese Ministry of Health, Labour and Welfare is $380 \mathrm{U} / \mathrm{kg} /$ day for patients with DIC.

\section{DATA SOURCE}

For this study, we used the Japanese Diagnosis Procedure Combination (DPC) inpatient database, previously described in detail elsewhere (21, 25-27). In short, this database includes administrative claims and discharge abstract data for all inpatients discharged from more than 1000 participating hospitals, including more than $90 \%$ of all tertiary-care hospitals in Japan (21, 25-27). The database contains baseline patient information at admission (day 0 ), such as age, sex, and consciousness level [Japan Coma Scale score: 0 (alert), 1-3 (delirious), 10-30 (somnolent), and 100-300 (comatose) points $(21,25-27)]$. The diagnoses were coded with the International Classification of Diseases 10th Revision codes as main disease, comorbidities at admission, and post-admission complications. Thus, the complications are clearly differentiated from the comorbidities already present in the database. The physicians in charge are obliged to record these diagnoses with reference to the medical charts to optimize the accuracy of the recorded diagnoses. The DPC database also includes the dosages and administration dates of all drugs and blood products administered during hospitalization. All interventional and surgical procedures are also coded with the original codes. The dates with the patients' status on hospital admission and at discharge are recorded as well (21, 25-27).

\section{PATIENT SELECTION}

We identified mechanically ventilated patients who required vasopressors and developed DIC after emergency open laparotomy for perforation of the lower intestinal tract as recorded in the DPC database from 1 July 2010 to 31 March 2013. The inclusion criteria were: (1) age of $\geq 15$ years; (2) confirmed diagnosis of perforation of the lower gastrointestinal tract at admission (coded in the "primary diagnosis" or "comorbidities at admission" section of the database); (3) performance of open abdominal laparotomy excluding exploratory laparotomy on day 0 or 1 ; (4) presence of septic shock, defined as use of vasopressors (noradrenaline and/or dopamine) started on day 0 or 1 ; (5) performance of mechanical ventilation after surgery on day 0 and/or 1 ; (6) initiation of antibiotic therapy on day 0 or 1; and (7) diagnosis of DIC (coded in the "main diagnosis" or "comorbidities at admission" section of the database). The exclusion criterion was initiation of rhTM on or after day 2 .

\section{VARIABLES AND ENDPOINTS}

In the current study, the hospital volume was defined as the number of eligible patients treated at each hospital and was subcategorized into tertiles. The hospital type was categorized as academic or non-academic.

The primary endpoint used was 28-day all-cause mortality. The secondary endpoints were ventilator-free days (VFDs) (28) and in-hospital mortality.

\section{STATISTICAL ANALYSIS}

We performed propensity-score matching analysis between the rhTM and control groups based on the estimated propensity score $(29,30)$. The propensity score was estimated using a logistic regression model for receipt of rhTM as a function of the following patient demographics and medication/interventions performed on day 0 or 1: age, gender, hospital type, hospital volume, Japan Coma Scale score, coexisting diseases, performance of blood culture, continuous renal replacement therapy/intermittent hemodialysis, catecholamine use (noradrenaline, dopamine, and/or dobutamine), vasopressin use, steroid use, intravenous immunoglobulin use, heparin use, use of other DIC medications available in Japan (i.e., antithrombin, ulinastatin, nafamostat mesilate, or gabexate mesilate), heparin use, initial use of two or more antibiotics, each types of antibiotics used, selective neutrophil elastase inhibitor use, albumin use, and blood transfusion $(1-3,12,21,25-27,31-34)$. We regarded the medication/interventions administered simultaneously with rhTM as "pre-rhTM treatments" because the critically ill status requiring these treatments was already present at the time of admission (21). We calculated the $C$-statistic to evaluate the goodness of fit. We performed a one-to-one matched analysis using nearestneighbor matching based on the estimated propensity scores of the patients. A match occurred when a patient in the rhTM group had an estimated score within 0.2 SD of a patient in the control group $(29,30)$. We defined absolute values of the standardized 
difference of more than $10 \%$ as out of balance (35), and examined the balance of baseline variables. We compared continuous variables using $t$-tests and categorical variables using the chi-squared test or Fisher's exact test. We examined the association between administration of rhTM and 28-day mortality using generalized estimating equations (GEE), accounting for the paired nature of the matched patients (36). We also performed Cox regression analysis to assess differences in in-hospital survival rates between patients with and without rhTM in the propensity-score-matched groups.

Instrumental variable analysis was also carried out as a confirmatory analysis of the propensity-score analyses. The hospitals' preference was used as an instrumental variable, and computed the differences in the 28-day mortality risk between the groups with and without rhTM, using two-stage least-squares method adjusted for the patients' characteristics $(21,25,26,37,38)$. We classified hospitals that administered rhTM to the $\geq 75$ th percentile of the eligible patients with DIC as hospitals with a preference for rhTM and those that administered rhTM to the $<75$ th percentile of the eligible patients with DIC as hospitals without a preference for rhTM (38). We estimated the risk difference and 95\% confidence interval $(95 \% \mathrm{CI})$ using the ivreg2 procedure of Stata/SE 13.0 (Stata Corp., College Station, TX, USA). A partial F-test was performed to confirm that the patterns of hospital use of rhTM is not a weak instrument (i.e., we examined the null hypothesis that "there was no association between patterns of hospital rhTM use and actual rhTM use") (37). An F-statistic of $>10$ indicates that the instrument is not weak (37). The IBM SPSS version 22 (IBM, Armonk, NY, USA) and Stata/SE 13.0 were used for all statistical analyses.

\section{RESULTS}

\section{PATIENTS}

Of 5443 mechanically ventilated patients with septic shock after surgically confirmed perforation of the lower intestine, 3271 patients were excluded (2963 due to DIC was not shown and 308 due to delayed start of rhTM). As depicted in Figure 1, 2202 patients (622 hospitals during the 33-month study period) were identified as eligible for the study. These patients were

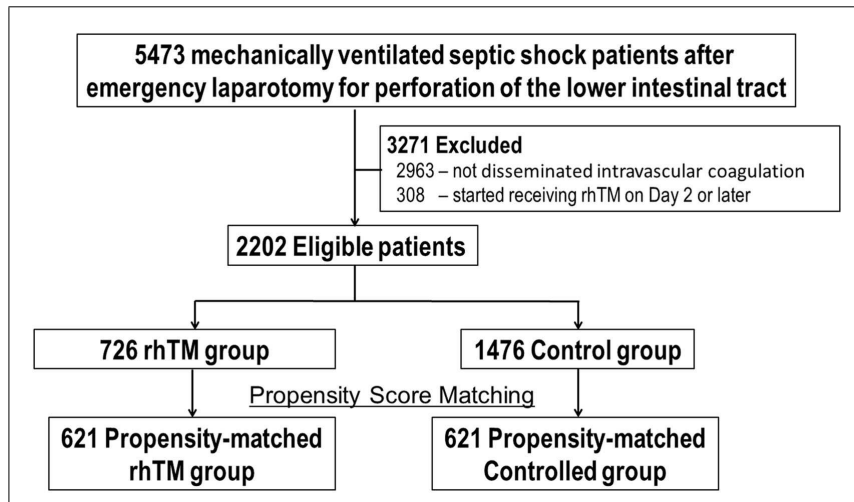

FIGURE 1 | Eligible patients undergoing propensity-score matching DIC, disseminated intravascular coagulation; rhTM, recombinant human soluble thrombomodulin. categorized into either an rhTM $(n=726)$ or control $(n=1476)$ group and underwent propensity-score matching, from which 621 propensity-score-matched pairs were generated. The $C$-statistic for the goodness of fit was 0.72 (95\% CI, 0.70-0.74) in the propensity-score model. The mean length of hospital stay was 44.8 days (95\% CI, 37-52).

Baseline characteristics of the unmatched and propensityscore-matched groups patients were shown in Tables 1 and 2. Patients were more likely to receive rhTM if they were admitted to an academic hospital or required renal replacement therapy, noradrenaline, carbapenem, antithrombin, immunoglobulin, sivelestat sodium, or blood transfusions when the unmatched groups were compared. After propensity-score matching were performed, all of the baseline patient characteristics were well balanced (i.e., the absolute value of the standardized differences $<10 \%$ ) between the groups.

\section{ENDPOINT}

The overall 28-day mortality rate was $24.1 \%$ (530/2202). No significant difference was documented in the 28 -day mortality rate between the two groups in the unmatched analysis [rhTM vs. control, $25.3 \%$ (184/726) vs. $23.4 \%$ (346/1476), respectively; difference, $1.9 \%$; $95 \% \mathrm{CI},-1.9$ to 5.7$]$ or in the propensityscore-matched analysis [rhTM vs. control, 26.1\% (162/621) vs. $24.8 \%$ (154/621), respectively; difference, $1.3 \%$; $95 \% \mathrm{CI},-3.6$ to 6.1]. The logistic GEE analysis showed no significant association between the use of rhTM and 28-day mortality in propensityscore-matched patients (OR, 1.1; 95\% CI, 0.82-1.4). In the instrumental variable model, the null hypothesis (i.e., no association between hospital rhTM use and actual rhTM use) was rejected with an $F$-statistic of 370 (i.e., $F$-statistic $>10, p<0.001$ ). The reduction in the 28-day mortality was not significantly associated with receipt of rhTM (risk difference, $-6.7 \%$; $95 \% \mathrm{CI},-16.4$ to 3.0 ).

We found no significant difference in the in-hospital mortality between the two groups of unmatched patients [rhTM vs. control, $35.7 \%(259 / 726)$ vs. $33.1 \%$ (489/1476), respectively; difference, $2.5 \%$; $95 \% \mathrm{CI},-1.7$ to 6.8 ]. Moreover, no significant difference was found among the propensity-score-matched patients [rhTM vs. control, $35.9 \%(223 / 621)$ vs. $34.3 \%$ (213/621), respectively; difference, $3.2 \%$; $95 \% \mathrm{CI},-3.7$ to 6.9 ]. Cox regression analysis showed no significant difference in in-hospital mortality between the two groups (hazard ratio, 1.1; 95\% CI, 0.88-1.3).

We found no significant difference in the number of VFDs between the rhTM group and control groups among either unmatched patients (14.0 vs. 14.7 days, respectively; difference, $-0.7 ; 95 \% \mathrm{CI},-1.7$ to 0.3 ) or propensity-score-matched patients (14.2 vs. 14.3 days, respectively; difference, -0.17 ; 95\% CI, -1.0 to 1.4$)$.

\section{DISCUSSION}

The current study suggests that there is no significant association between rhTM use and 28-day mortality in sepsis-induced DIC patients after laparotomy for intestinal perforation. Additionally, no significant difference was documented in the VFDs between the rhTM and control groups.

Anticoagulant therapy agents, such as antithrombin (39-41) and recombinant APC (42), have been evaluated as additional 
Table 1 | Baseline patient characteristics in the unmatched and propensity-score-matched groups.

\begin{tabular}{|c|c|c|c|c|c|c|}
\hline & \multicolumn{3}{|c|}{ Unmatched groups } & \multicolumn{3}{|c|}{ Propensity-score-matched groups } \\
\hline & $\begin{array}{l}\text { Control } \\
(n=1476)\end{array}$ & $\begin{array}{l}\text { rhTM } \\
(n=726)\end{array}$ & $\begin{array}{l}\text { Standardized } \\
\text { difference, \% }\end{array}$ & $\begin{array}{l}\text { Control } \\
(n=621)\end{array}$ & $\begin{array}{l}\text { rhTM } \\
(n=621)\end{array}$ & $\begin{array}{l}\text { Standardized } \\
\text { difference, \% }\end{array}$ \\
\hline \multicolumn{7}{|l|}{ Age (years) } \\
\hline $18-50$ & $52(3.5)$ & $18(2.5)$ & 6.1 & $13(2.1)$ & $14(2.3)$ & -1.1 \\
\hline $51-60$ & $102(6.9)$ & $41(5.6)$ & 5.2 & $35(5.6)$ & $37(6.0)$ & -1.4 \\
\hline $71-80$ & $472(32.0)$ & $234(32.2)$ & -0.5 & $205(33.0)$ & $203(32.7)$ & 0.7 \\
\hline$\geq 81$ & $580(39.3)$ & $291(40.1)$ & -1.6 & 248 (39.9) & $255(41.1)$ & -2.3 \\
\hline Sex (male) & $733(49.7)$ & $354(48.8)$ & 1.8 & $310(49.9)$ & $300(48.3)$ & 3.2 \\
\hline Hospital type (academic) & $363(24.6)$ & $235(32.4)$ & -17.3 & $200(32.2)$ & $187(30.1)$ & 4.5 \\
\hline \multicolumn{7}{|l|}{ Hospital volume, cases } \\
\hline Low, 1-7 & $639(43.3)$ & $271(37.3)$ & 12.2 & $242(39.0)$ & $244(39.3)$ & -0.7 \\
\hline \multicolumn{7}{|l|}{ Consciousness level (JCS score) } \\
\hline Alert & $1003(68.0)$ & $466(64.2)$ & 8.0 & $407(65.5)$ & $406(65.4)$ & 0.3 \\
\hline Delirious & $248(16.8)$ & $144(19.8)$ & -7.8 & 109 (17.6) & $116(18.7)$ & -2.9 \\
\hline Somnolent & $99(6.7)$ & $50(6.9)$ & -0.7 & $39(6.3)$ & $41(6.6)$ & -1.3 \\
\hline Comatose & $126(8.5)$ & $66(9.1)$ & -2.0 & $66(10.6)$ & $58(9.3)$ & 4.3 \\
\hline \multicolumn{7}{|l|}{ Coexisting disease } \\
\hline Diabetes & $140(9.5)$ & $76(10.5)$ & -3.3 & $72(11.6)$ & $56(9.0)$ & 8.5 \\
\hline Old myocardial infarction & $20(1.4)$ & $12(1.7)$ & -2.4 & $10(1.6)$ & $10(1.6)$ & 0.0 \\
\hline Chronic obstructive pulmonary disease & $44(3.0)$ & $18(2.5)$ & 3.1 & $17(2.7)$ & $17(2.7)$ & 0.0 \\
\hline Pneumonia & $96(6.5)$ & $43(5.9)$ & 2.4 & $36(5.8)$ & $39(6.3)$ & -2.0 \\
\hline Liver cirrhosis & $19(1.3)$ & $2(0.3)$ & 11.5 & $2(0.3)$ & $2(0.3)$ & 0.0 \\
\hline Chronic renal failure & $111(7.5)$ & $51(7.0)$ & 1.9 & $49(7.9)$ & $46(7.4)$ & 1.8 \\
\hline
\end{tabular}

therapies to reduce the high mortality rates associated with severe sepsis and septic shock. Antithrombin supplementation as an adjunct therapy in patients with sepsis-induced DIC was suggested in the 1990s $(40,41)$. However, the largest randomized trial, the KyberSept Trial (43), could not prove beneficial effects of highdose antithrombin therapy on mortality. Moreover, meta-analyses of randomized trials concluded that antithrombin could not be generally recommended for critically ill patients, including those with severe sepsis (44). Conversely, Bernard et al. (42) suggested the efficacy of APC on survival in patients with severe sepsis in 2001. However, APC was withdrawn from the market after the Prospective Recombinant Human APC Worldwide Evaluation in Severe Sepsis and Septic Shock trial documented its failure (45). Thus, the latest Surviving Sepsis Campaign Guidelines (3), the major international guidelines for severe sepsis, do not recommend the use of antithrombin and APC for patients with severe sepsis.

A novel anticoagulant therapy, rhTM, was developed for patients with DIC in Japan. Several studies have investigated the use of rhTM for sepsis-induced DIC in Japan, which is the only country where rhTM is widely used for clinical treatment of DIC (46-51). Several positive effects of rhTM were reported in these studies (46-51). Additionally, Vincent et al. (18) reported that rhTM was associated with beneficial pharmacologic effects and is a safe intervention in critically ill patients with sepsis-induced coagulopathy. Thus, rhTM seems to be a promising drug for sepsis-induced DIC.

Previous studies have suggested that patients with respiratory and/or cardiac dysfunction and evidence of DIC appear to receive the greatest rhTM-related survival benefit $(13,17,18,47,51,52)$. Therefore, in the current study, we selected patients with DIC who required vasopressor and mechanical ventilation after emergency open laparotomy for perforation of the lower intestinal tract. The strength of the current study is the evaluation of more than 2000 patients using data throughout Japan. We used a propensityscore matching approach to overcome the bias associated with the measured confounding factors. After propensity-score matching, the selected patients were well balanced with regard to baseline characteristics, including factors with the potential to affect mortality in patients with septic shock after emergency laparotomy, as presented in Tables 1 and 2 . We then attempted to construct a "randomized experiment-like situation," and compared groups with similar characteristics and conditions without specifying the relationships between measured confounding factors and outcomes. However, we failed to confirm our hypothesis that rhTM is associated with better survival and with reducing VFDs in the propensity-score-matched analyses. Recent studies indicated that rhTM acts as an anticoagulant with anti-inflammatory properties that may prevent later occurrence of multiple organ failure $(12,49,53)$. However, we could not demonstrate this effect when 
Table 2 | Medications and interventions performed on day 0 or 1 in the unmatched and propensity-score-matched groups.

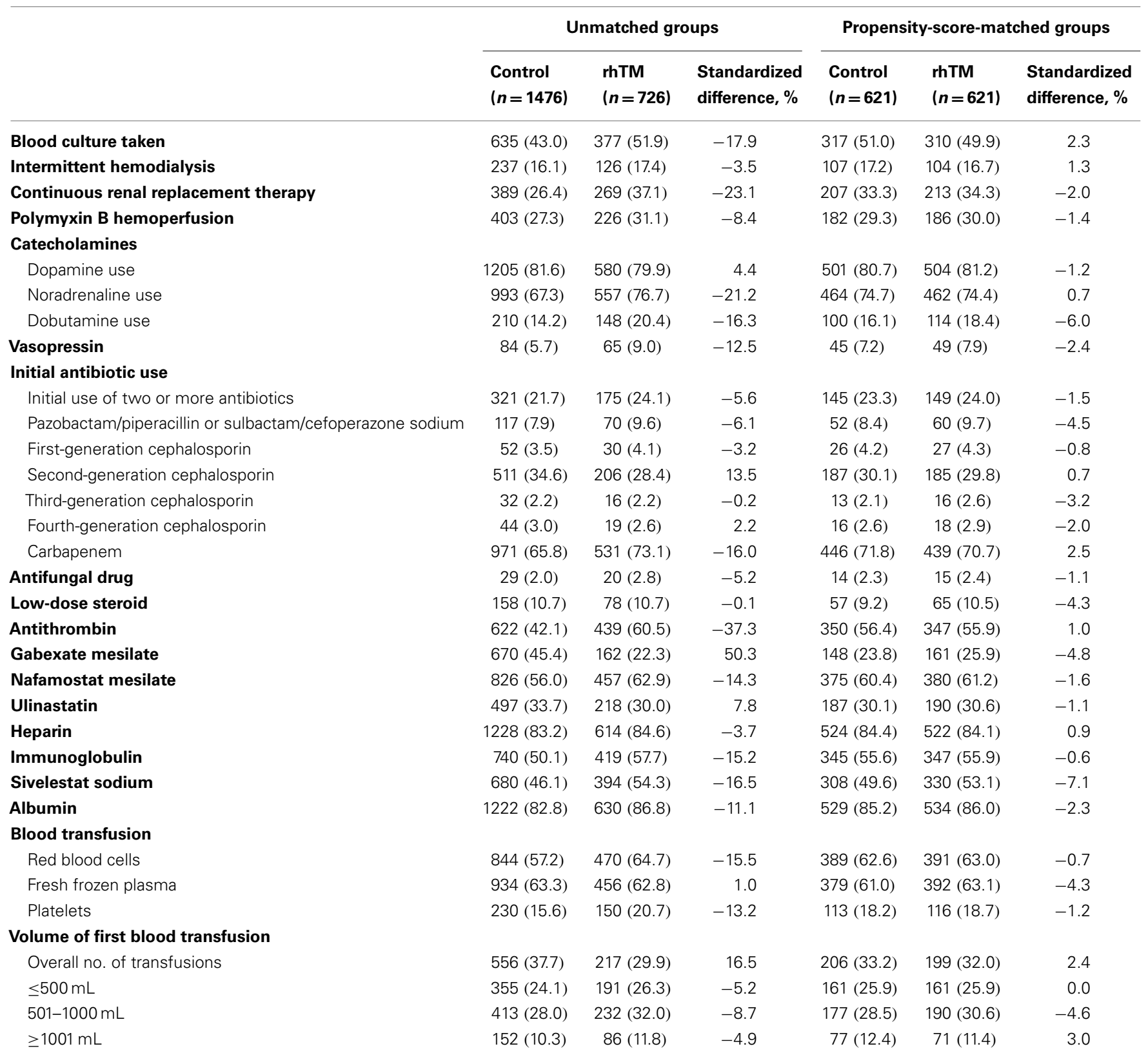

rhTM, recombinant human soluble thrombomodulin.

analyzing our data. Although the number of VFDs should have represented the recovery of pulmonary failure in the patients in the current study, there was no significant difference in the number of VFDs between the rhTM and control groups. These findings are consistent with the results obtained by logistic GEE and Cox regression analyses. Moreover, we performed also instrumental variable analysis to address the bias of confounding factors that were not unmeasured, and the outcome of this analysis confirmed the robustness of the results.

The current results are consistent with those of two randomized trials in patients with sepsis-induced DIC $(13,18)$ as well as with our previous large retrospective study that evaluated patients with severe pneumonia with sepsis-induced DIC (21), all of which reported non-significant mortality trends in favor of rhTM. However, we could not obtain any objective coagulation status data from the database, including platelet counts, D-dimer or fibrinogen levels, and DIC scores. The scoring systems for DIC, which exhibit various differences, were used as an inclusion criterion and quantitatively evaluated in previous studies $(13,17,18,51)$. Thus, we must wait for the results of an ongoing multinational phase-3 trial (ClinicalTrials.gov Identifier: NCT01598831) before drawing any further conclusions.

There are some limitations in the current study. First, our study was performed retrospectively without randomization. Although 
a propensity-score method was used to adjust for measured confounding factors, bias could inevitably exist in the form of confounders that were not measured. For example, although approximately $20 \%$ of patients were administered dobutamine, the necessary information for calculating cardiac index of the patients was not available in the database. More importantly, DIC scores, which may indicate the severity of DIC, were also unavailable. We therefore performed instrumental variable analyses to compensate for these potentially unmeasured confounders. Second, the definition of septic shock in the current study might be vague. Vasopressors might be used for types of shock other than septic shock. Additionally, according to the Surviving Sepsis Campaign 2012 (3), septic shock is defined as "sepsis-induced hypotension persisting despite adequate fluid resuscitation.” In the current study, we used a surrogate definition because the term "adequate" could not be accurately evaluated from the information in the database. However, we believe that if the physician in charge determined that fluid resuscitation was not "adequate" in patients with septic shock, the next step for resuscitation must be the use of vasopressors according to the guidelines. This explains the definition of septic shock used in the current study. Third, we could not determine the exact time when rhTM was administered. We therefore could not identify if the variables used in the propensity-score estimation were pre- or post-rhTM treatment. In the latter case, those variables could not be used for estimating the propensity-score $(21,54,55)$. However, rhTM has a long half-life of $20 \mathrm{~h}$. Therefore, rhTM could not have affected the other interventions/medications within days 0 and 1 (12, 13, 17, 21, 56-58). Fourth, we only evaluated mechanically ventilated patients with concurrent septic shock and DIC after surgery for intestinal perforation. As a result, only a few patients in this strictly selected population were included from each hospital. Because they were from various institutions, they might not have been uniformly monitored and treated. Additionally, the results cannot be generalized to patients with other causes of abdominal sepsis such as cholangitis, cholecystitis, and pancreatitis. Fifth, the selective use of concurrent dugs affecting coagulation, including antithrombin, gabexate mesilate, nafamostat mesilate, and heparin, may have affected the results of the study, although the proportions of these drugs were well balanced between the rhTM and control groups after propensity-score matching. These drugs might be used for the treatment of a variety of conditions in critical care other than DIC therapy (e.g., treatment of pancreatitis or anticoagulation for hemodialysis and/or placement of an arterial line).

\section{CONCLUSION}

We found no association between administration of rhTM and 28-day mortality in mechanically ventilated patients with septic shock and concurrent DIC after intestinal perforation. Prospective randomized trials are required to confirm our findings.

\section{AUTHOR CONTRIBUTIONS}

TT contributed to study design, statistical analyses, and review and drafting of the manuscript. HM contributed to study design, data acquisition, statistical analyses, and review of the manuscript. KF contributed to study design, data acquisition, and review of the manuscript. HY contributed to study design, statistical analyses, data acquisition, and review and drafting of the manuscript. All authors read and approved the final version of the manuscript.

\section{ACKNOWLEDGMENTS}

Prof. Fushimi and Prof. Yasunaga received grant support from the Ministry of Health, Labour and Welfare of Japan (Research on Policy Planning and Evaluation, grant H26-Policy-011). The funders had no role in the execution of this study or interpretation of the results.

\section{REFERENCES}

1. Angus DC, Linde-Zwirble WT, Lidicker J, Clermont G, Carcillo J, Pinsky MR. Epidemiology of severe sepsis in the United States: analysis of incidence, outcome, and associated costs of care. Crit Care Med (2001) 29(7):1303-10. doi:10.1097/00003246-200107000-00002

2. Angus DC, van der Poll T. Severe sepsis and septic shock. N Engl J Med (2013) 369(9):840-51. doi:10.1056/NEJMra1208623

3. Dellinger RP, Levy MM, Rhodes A, Annane D, Gerlach H, Opal SM, et al. Surviving sepsis campaign: international guidelines for management of severe sepsis and septic shock: 2012. Crit Care Med (2013) 41(2):580-637. doi:10.1097/CCM. ob013e31827e83af

4. Linner A, Sunden-Cullberg J, Johansson L, Hjelmqvist H, Norrby-Teglund A, Treutiger CJ. Short- and long-term mortality in severe sepsis/septic shock in a setting with low antibiotic resistance: a prospective observational study in a Swedish university hospital. Front Public Health (2013) 1:51. doi:10.3389/fpubh. 2013.00051

5. Levi M, Ten Cate H. Disseminated intravascular coagulation. N Engl J Med (1999) 341(8):586-92. doi:10.1056/NEJM199908193410807

6. Hunt BJ. Bleeding and coagulopathies in critical care. N Engl J Med (2014) 370(9):847-59. doi:10.1056/NEJMra1208626

7. Gando S, Iba T, Eguchi Y, Ohtomo Y, Okamoto K, Koseki K, et al. A multicenter, prospective validation of disseminated intravascular coagulation diagnostic criteria for critically ill patients: comparing current criteria. Crit Care Med (2006) 34(3):625-31. doi:10.1097/01.ccm.0000202209.42491.38

8. Gando S, Saitoh D, Ogura H, Mayumi T, Koseki K, Ikeda T, et al. Natural history of disseminated intravascular coagulation diagnosed based on the newly established diagnostic criteria for critically ill patients: results of a multicenter, prospective survey. Crit Care Med (2008) 36(1):145-50. doi:10.1097/01.CCM. 0000295317.97245.2D

9. Levi M, Toh CH, Thachil J, Watson HG. Guidelines for the diagnosis and management of disseminated intravascular coagulation. British Committee for Standards in Haematology. Br J Haematol (2009) 145(1):24-33. doi:10.1111/j. 1365-2141.2009.07600.x

10. Semeraro N, Ammollo CT, Semeraro F, Colucci M. Sepsis, thrombosis and organ dysfunction. Thromb Res (2012) 129(3):290-5. doi:10.1016/j.thromres.2011.10. 013

11. Thachil J, Toh CH. Current concepts in the management of disseminated intravascular coagulation. Thromb Res (2012) 129(Suppl 1):S54-9. doi:10.1016/ S0049-3848(12)70017-8

12. Iba T, Gando S, Thachil J. Anticoagulant therapy for sepsis-associated disseminated intravascular coagulation: the view from Japan. J Thromb Haemost (2014) 12(7):1010-9. doi:10.1111/jth.12596

13. Saito H, Maruyama I, Shimazaki S, Yamamoto Y, Aikawa N, Ohno R, et al. Efficacy and safety of recombinant human soluble thrombomodulin (ART123) in disseminated intravascular coagulation: results of a phase III, randomized, double-blind clinical trial. J Thromb Haemost (2007) 5(1):31-41. doi:10.1111/j.1538-7836.2006.02267.x

14. Iba T, Aihara K, Watanabe S, Yanagawa Y, Takemoto M, Yamada A, et al. Recombinant thrombomodulin improves the visceral microcirculation by attenuating the leukocyte-endothelial interaction in a rat LPS model. Thromb Res (2013) 131(4):295-9. doi:10.1016/j.thromres.2012.11.025

15. Faust SN, Heyderman RS, Levin M. Coagulation in severe sepsis: a central role for thrombomodulin and activated protein C. Crit Care Med (2001) 29(7 Suppl):S62-7. doi:10.1097/00003246-200107001-00022

16. Maruyama I. Recombinant thrombomodulin and activated protein $C$ in the treatment of disseminated intravascular coagulation. Thromb Haemost (1999) 82(2):718-21. 
17. Aikawa N, Shimazaki S, Yamamoto Y, Saito H, Maruyama I, Ohno R, et al. Thrombomodulin alfa in the treatment of infectious patients complicated by disseminated intravascular coagulation: subanalysis from the phase 3 trial. Shock (2011) 35(4):349-54. doi:10.1097/SHK.0b013e318204c019

18. Vincent JL, Ramesh MK, Ernest D, Larosa SP, Pachl J, Aikawa N, et al. A randomized, double-blind, placebo-controlled, phase $2 \mathrm{~b}$ study to evaluate the safety and efficacy of recombinant human soluble thrombomodulin, ART-123, in patients with sepsis and suspected disseminated intravascular coagulation. Crit Care Med (2013) 41(9):2069-79. doi:10.1097/CCM.0b013e31828e9b03

19. Ani C, Farshidpanah S, Bellinghausen Stewart A, Nguyen HB. Variations in organism-specific severe sepsis mortality in the United States. Crit Care Med (2015) 43(1):65-77. doi:10.1097/ccm.0000000000000555

20. Friend KE, Burgess JN, Britt RC, Collins JN, Weireter LN, Novosel TJ, et al. Procalcitonin elevation suggests a septic source. Am Surg (2014) 80(9):906-9.

21. Tagami T, Matsui H, Horiguchi H, Fushimi K, Yasunaga H. Recombinant human soluble thrombomodulin and mortality in severe pneumonia patients with sepsis-associated disseminated intravascular coagulation: an observational nationwide study. J Thromb Haemost (2015) 13:31-40. doi:10.1111/jth.12786

22. Wada H, Asakura H, Okamoto K, Iba T, Uchiyama T, Kawasugi K, et al. Expert consensus for the treatment of disseminated intravascular coagulation in Japan. Thromb Res (2010) 125(1):6-11. doi:10.1016/j.thromres.2009.08.017

23. Gando S, Saitoh D, Ishikura H, Ueyama M, Otomo Y, Oda S, et al. A randomized, controlled, multicenter trial of the effects of antithrombin on disseminated intravascular coagulation in patients with sepsis. Crit Care (2013) 17(6):R297. doi:10.1186/cc13163

24. Iba T, Saito D, Wada H, Asakura H. Efficacy and bleeding risk of antithrombin supplementation in septic disseminated intravascular coagulation: a prospective multicenter survey. Thromb Res (2012) 130(3):e129-33. doi:10.1016/j.thromres. 2012.03.021

25. Tagami T, Matsui H, Horiguchi H, Fushimi K, Yasunaga H. Antithrombin and mortality in severe pneumonia patients with sepsis-associated disseminated intravascular coagulation: an observational nationwide study. JThromb Haemost (2014) 12(9):1470-9. doi:10.1111/jth.12643

26. Tagami T, Matsui H, Horiguchi H, Fushimi K, Yasunaga H. Low-dose corticosteroid use and mortality in severe community-acquired pneumonia patients. Eur Respir J (2015) 45(2):463-72. doi:10.1183/09031936.00081514

27. Tagami T, Matsui H, Horiguchi H, Fushimi K, Yasunaga H. Thoracic aortic injury in Japan: a nationwide retrospective cohort study. Circ J (2015) 79(1):55-60. doi:10.1253/circj.CJ-14-0916

28. Schoenfeld DA, Bernard GR. Statistical evaluation of ventilator-free days as an efficacy measure in clinical trials of treatments for acute respiratory distress syndrome. Crit Care Med (2002) 30(8):1772-7. doi:10.1097/00003246-20020800000016

29. Griswold ME, Localio AR, Mulrow C. Propensity score adjustment with multilevel data: setting your sites on decreasing selection bias. Ann Intern Med (2010) 152(6):393-5. doi:10.7326/0003-4819-152-6-201003160-00010

30. Rosenbaum P, Rubin D. Constructing a control-group using multivariate matched sampling methods that incorporate the propensity score. Am Stat (1985) 39:33-8. doi:10.1097/MCG.0b013e3182431d78

31. Iba T, Nagaoka I, Boulat M. The anticoagulant therapy for sepsis-associated disseminated intravascular coagulation. Thromb Res (2013) 131(5):383-9. doi:10.1016/j.thromres.2013.03.012

32. Iwagami M, Yasunaga H, Doi K, Horiguchi H, Fushimi K, Matsubara T, et al. Postoperative polymyxin $\mathrm{B}$ hemoperfusion and mortality in patients with abdominal septic shock: a propensity-matched analysis. Crit Care Med (2013) 42(5):1187-93. doi:10.1097/CCM.0000000000000150

33. Yasunaga H, Horiguchi H, Hashimoto H, Matsuda S, Fushimi K. Effect and cost of treatment for acute pancreatitis with or without gabexate mesylate: a propensity score analysis using a nationwide administrative database. Pancreas (2013) 42(2):260-4. doi:10.1097/MPA.0b013e31826495a0

34. Tagami T, Tosa R, Omura M, Fukushima H, Kaneko T, Endo T, et al. Effect of a selective neutrophil elastase inhibitor on mortality and ventilator-free days in patients with increased extravascular lung water: a post hoc analysis of the PiCCO Pulmonary Edema Study. J Intensive Care (2014) 2(69):69. doi:10.1186/s40560-014-0067-y

35. Austin PC. The use of propensity score methods with survival or time-to-event outcomes: reporting measures of effect similar to those used in randomized experiments. Stat Med (2014) 33(7):1242-58. doi:10.1002/sim.5984
36. Austin PC. A critical appraisal of propensity-score matching in the medical literature between 1996 and 2003. Stat Med (2008) 27(12):2037-49. doi:10.1002/sim.3150

37. Staiger D, Stock JH. Instrumental variables regression with weak instruments. Econometrica (1994) 65(3):557-86. doi:10.2307/2171753

38. Bateman BT, Bykov K, Choudhry NK, Schneeweiss S, Gagne JJ, Polinski JM, et al. Type of stress ulcer prophylaxis and risk of nosocomial pneumonia in cardiac surgical patients: cohort study. BMJ (2013) 347:f5416. doi:10.1136/bmj. f5416

39. Fourrier F, Chopin C, Huart JJ, Runge I, Caron C, Goudemand J. Doubleblind, placebo-controlled trial of antithrombin III concentrates in septic shock with disseminated intravascular coagulation. Chest (1993) 104(3):882-8. doi:10.1378/chest.104.3.882

40. Baudo F, Caimi TM, de Cataldo F, Ravizza A, Arlati S, Casella G, et al. Antithrombin III (ATIII) replacement therapy in patients with sepsis and/or postsurgical complications: a controlled double-blind, randomized, multicenter study. Intensive Care Med (1998) 24(4):336-42. doi:10.1007/s001340050576

41. Eisele B, Lamy M, Thijs LG, Keinecke HO, Schuster HP, Matthias FR, et al. Antithrombin III in patients with severe sepsis. A randomized, placebo-controlled, double-blind multicenter trial plus a meta-analysis on all randomized, placebo-controlled, double-blind trials with antithrombin III in severe sepsis. Intensive Care Med (1998) 24(7):663-72. doi:10.1007/ s001340050642

42. Bernard GR, Vincent JL, Laterre PF, LaRosa SP, Dhainaut JF, Lopez-Rodriguez A, et al. Efficacy and safety of recombinant human activated protein C for severe sepsis. N Engl J Med (2001) 344(10):699-709. doi:10.1056/ nejm200103083441001

43. Warren BL, Eid A, Singer P, Pillay SS, Carl P, Novak I, et al. Caring for the critically ill patient. High-dose antithrombin III in severe sepsis: a randomized controlled trial. JAMA (2001) 286(15):1869-78. doi:10.1001/jama.286.15.1869

44. Afshari A, Wetterslev J, Brok J, Moller A. Antithrombin III in critically ill patients: systematic review with meta-analysis and trial sequential analysis. BMJ (2007) 335(7632):1248-51. doi:10.1136/bmj.39398.682500.25

45. Ranieri VM, Thompson BT, Barie PS, Dhainaut JF, Douglas IS, Finfer S, et al. Drotrecogin alfa (activated) in adults with septic shock. N Engl J Med (2012) 366(22):2055-64. doi:10.1056/NEJMoa1202290

46. Kawano N, Yoshida S, Ono N, Himeji D, Nagahiro Y, Sayaka K, et al. Clinical features and outcomes of 35 disseminated intravascular coagulation cases treated with recombinant human soluble thrombomodulin at a single institution. J Clin Exp Hematop (2011) 51(2):101-7. doi:10.3960/jslrt.51.101

47. Yamakawa K, Fujimi S, Mohri T, Matsuda H, Nakamori Y, Hirose T, et al. Treatment effects of recombinant human soluble thrombomodulin in patients with severe sepsis: a historical control study. Crit Care (2011) 15(3):R123. doi:10.1186/cc10228

48. Hayakawa M, Yamamoto H, Honma T, Mukai N, Higashiyama A, Sugano M, et al. Pharmacokinetics and pharmacodynamics of recombinant soluble thrombomodulin in disseminated intravascular coagulation patients with renal impairment. Shock (2012) 37(6):569-73. doi:10.1097/SHK. 0b013e318252bc82

49. Ogawa Y, Yamakawa K, Ogura H, Kiguchi T, Mohri T, Nakamori Y, et al. Recombinant human soluble thrombomodulin improves mortality and respiratory dysfunction in patients with severe sepsis. J Trauma Acute Care Surg (2012) 72(5):1150-7. doi:10.1097/TA.0b013e3182516ab5

50. Kato T, Sakai T, Kato M, Hagihara M, Hasegawa T, Matsuura K, et al. Recombinant human soluble thrombomodulin administration improves sepsis-induced disseminated intravascular coagulation and mortality: a retrospective cohort study. Thromb J (2013) 11(1):3. doi:10.1186/1477-9560-11-3

51. Yamakawa K, Ogura H, Fujimi S, Morikawa M, Ogawa Y, Mohri T, et al. Recombinant human soluble thrombomodulin in sepsis-induced disseminated intravascular coagulation: a multicenter propensity score analysis. Intensive Care Med (2013) 39(4):644-52. doi:10.1007/s00134-013-2822-2

52. Fink MP. Recombinant soluble thrombomodulin as an adjunctive treatment for sepsis and disseminated intravascular coagulation: relatively safe and possibly effective. Crit Care Med (2013) 41(9):2221-3. doi:10.1097/CCM. 0b013e3182964037

53. Oda S, Aibiki M, Ikeda T, Imaizumi H, Endo S, Ochiai R, et al. The Japanese guidelines for the management of sepsis. J Intensive Care (2014) 2(55):55. doi:10.1186/s40560-014-0055-2 
54. Sauer BC, Brookhart MA, Roy J, VanderWeele T. A review of covariate selection for non-experimental comparative effectiveness research. Pharmacoepidemiol Drug Saf (2013) 22(11):1139-45. doi:10.1002/pds.3506

55. Pattanayak CW, Rubin DB, Zell ER. Propensity score methods for creating covariate balance in observational studies. Rev Esp Cardiol (2011) 64(10):897-903. doi:10.1016/j.recesp.2011.06.008

56. Nakashima M, Kanamaru M, Umemura K, Tsuruta K. Pharmacokinetics and safety of a novel recombinant soluble human thrombomodulin, ART-123, in healthy male volunteers. J Clin Pharmacol (1998) 38(1):40-4. doi:10.1002/j. 1552-4604.1998.tb05792.x

57. Moll S, Lindley C, Pescatore S, Morrison D, Tsuruta K, Mohri M, et al. Phase I study of a novel recombinant human soluble thrombomodulin, ART123. J Thromb Haemost (2004) 2(10):1745-51. doi:10.1111/j.1538-7836.2004. 00927.x

58. Mohri M, Sugimoto E, Sata M, Asano T. The inhibitory effect of recombinant human soluble thrombomodulin on initiation and extension of coagulation - a comparison with other anticoagulants. Thromb Haemost (1999) 82(6):1687-93.
Conflict of Interest Statement: The authors declare that the research was conducted in the absence of any commercial or financial relationships that could be construed as a potential conflict of interest.

Received: 22 December 2014; accepted: 08 February 2015; published online: 26 February 2015.

Citation: Tagami T, Matsui H, Fushimi K and Yasunaga H (2015) Use of recombinant human soluble thrombomodulin in patients with sepsis-induced disseminated intravascular coagulation after intestinal perforation. Front. Med. 2:7. doi: 10.3389/fmed.2015.00007

This article was submitted to Intensive Care Medicine and Anesthesiology, a section of the journal Frontiers in Medicine.

Copyright (C) 2015 Tagami, Matsui, Fushimi and Yasunaga. This is an open-access article distributed under the terms of the Creative Commons Attribution License (CC BY). The use, distribution or reproduction in other forums is permitted, provided the original author(s) or licensor are credited and that the original publication in this journal is cited, in accordance with accepted academic practice. No use, distribution or reproduction is permitted which does not comply with these terms. 